\title{
Protocol Error Artifact
}

National Cancer Institute

\section{Source}

National Cancer Institute. Protocol Error Artifact. NCI Thesaurus. Code C87045.

An image of reduced quality resulting from the use of incorrect or incomplete instructions. 